\title{
Integrated reporting: the state of the art of Corporate Reporting
}

\author{
Chiara Mio ${ }^{1}$ \\ (D) https://orcid.org/0000-0003-0945-0334 \\ Email: mio@unive.it \\ ${ }^{1}$ Università Ca' Foscari Venezia, Dipartimento di Management, Venezia, Italy
}

Correspondence address

Chiara Mio

Università Ca' Foscari Venezia, Dipartimento di Management

Dorsoduro 3246, 30123

Venezia - Italy

\section{INTRODUCTION}

The stream of accounting research on nonfinancial and voluntary disclosure has been developing a lot in the last five years, also due to the introduction of Integrated Reporting (IR) in 2013 (International Integrated Reporting Council [IIRC], 2013). This increase in academic research has been mirroring an equally lively debate at the standard setter and policy maker level, which has been tackling several issues concerning the nature of nonfinancial information, the standards to be adopted and the regulation of such disclosure. As a consequence, academic research in this area has the potential to significantly contribute to practice. I first discuss the evolution of Corporate Reporting, then I focus on Integrated Reporting, which is the state of the art of Corporate Reporting and, finally, an overview of previous investigations and some suggestions for future studies were provided.

\section{CORPORATE REPORTING}

Accounting principles are often seen as totally disconnected from the economic and business context in which corporations operate. However, these principles are influenced by the evolutions of the business landscape and consequently by the needs of capital markets. For instance, fair value accounting has been driven by investors' need to take faster decisions. This was made possible by fair value accounting, which already reflects market information.

More recently, reporting and - afterwards - accounting has been shifting towards nonfinancial information (NFI) disclosure because of market pressures. At first, this evolution has been voluntary. According to Daub (2007) "a report can be considered a sustainability report in the strictest sense of the term if it is public and tells the reader how the company is meeting the corporate sustainability challenges. It must, in other words, contain qualitative and quantitative information on the extent to which the company has managed to improve its economic, environmental and social effectiveness and efficiency in the reporting period and to integrate these aspects in a sustainability management system" (p. 77). Many companies published their Sustainability Report following some guidelines (among them, the Global Reporting Initiative guidelines are probably the most influential). Recently, NFI became mandatory in some countries, with the European legislator issuing Directive 2014/95/EU on nonfinancial disclosure. This regulatory evolution is hugely important, because it equals nonfinancial and financial disclosure in terms of obligatoriness, assurance, and compliance. 
Also, in the case of NFI disclosure, the evolution of accounting can be traced back to changes in the economic context and, as a consequence, to the capital market information needs. In the current business environment, corporate value creation is more and more influenced by externalities that go beyond the market logic and that are, therefore, difficult to measure in monetary terms. To generate value, companies rely on intangible assets, such as corporate reputation, human capital, and know how. Until the 1990s, most of the companies' market capitalization was due to tangible assets, because such assets represented the key success factor in the value creation process. The situation changed after 2000s, with technological and social evolution, leading to a great (sometimes disruptive) economic development, and with intangibles being the key factors in value creation processes.

Traditional annual reports are unable to provide investors with enough relevant information to forecast the ability of corporations to create value in the long term. In short, the economic environment changed dramatically in the last 20 years. Accounting needs to change accordingly. Consider, for instance, the case of a company holding a patent. To determine its real value and the contribution it may be able to provide to the company's value creation process, we would need to know how many years the patent will still be effective, whether other competitors own similar patents, if the market evolution will confer more value to the patent in the future, among others. To this extent, the historical cost does not provide enough information, and the fair value is scarcely relevant if we do not know the assumption leading to a certain fair value evaluation (assumptions that often are nonfinancial).

In this new economic and competitive context, which creates new information needs for investors, accounting needs to focus on Corporate Reporting as the new paradigm, thus holistically considering financial, nonfinancial and narrative reporting, corporate governance, remuneration, and sustainability reporting. Sustainability Reporting had (and has) some severe shortcomings, which is evidenced by the fact that stakeholders and investors do not normally consider the information contained in such reports when making their decisions. Instead, nonfinancial and financial information need to be communicated holistically by corporations through their Corporate Reporting system. Financial and nonfinancial issues are, in the current business environment, tightly related and integrated, to the point that the distinction between the two categories no longer has sense. Investors need to have a holistic picture of the company, which allows them to have information on the value creation process in the short, medium and long term.

\section{INTEGRATED REPORTING}

From this perspective, Integrated Reporting (IR) can be seen as one possible type (although not necessarily the best) of Corporate Reporting. Differently from other forms of reporting, it is not an additional but rather an overall and holistic component of the system. IR is intended to connect and bring together all the different components of the Corporate Reporting. The International Integrated Reporting Committee (IIRC), in its 2013 framework, defines IR as "a concise communication about how an organization's strategy, governance, performance and prospects, in the context of its external environment, create value over the short, medium and long term" (IIRC, 2013, p. 7).

The backbones of the IR Framework are the content elements (organizational overview and external environment; governance; business model; risks and opportunities; strategy and resource allocation; performance; and outlook) and the guiding principles (strategic focus and future orientation; connectivity of information; stakeholder relationships; materiality; conciseness; reliability and completeness; consistency and comparability). Among those, the most innovative are arguably the following: business model, forward-looking approach, and materiality.

The IR Framework requires companies to disclose information about their business model, defined by the IR Framework as "the chosen system of inputs, business activities, outputs and outcomes that aims to create value over the short, medium and long term" (IIRC, 2013, p. 14). Business model analysis is central for investors to assess the ability of the company to create and sustain value over time. This is true in any kind of business but even more in innovative companies.

The "strategic focus and the future orientation" guiding principles require that an IR provides insight into the organization's strategy and as to how this relates to its ability to create value in the short, medium and long term and to its use of and effects on the capitals. This principle also represents one of the most important innovations introduced by IR, which may benefit investors the most. 
Annual reports have been traditionally reporting past events, while the value of companies depends on the ability to generate value in the future.

Finally, the IIRC defines materiality as follows: "a matter is material if it could substantively affect the organization's ability to create value in the short, medium or long term" (IIRC, 2013, p. 33). This approach to materiality is significantly different compared with the sustainability reporting approach, because the market is at the center of the definition and not stakeholders. This difference can also be explained by relying on the institutional theory (Besharov \& Smith, 2014; Dunn \& Jones, 2010), which argues that organizations operate in pluralistic environments, characterized by multiple institutional logics. From this perspective, the most prominent logic in IR materiality is the market logic, while in sustainability reporting is stakeholder logic.
The common root of the guiding principles and content elements briefly discussed above (business model, future orientation, and materiality) is not stemming from the reporting but rather from the philosophical background of IR. The cornerstone of IR is the integrated thinking approach, defined - conversely to the silo thinking approach - as the active consideration by an organization of the relationships between its various operating and functional units and the capitals that the organization uses and affects. Integrated thinking leads to integrated decision-making and to actions that consider the creation of value over the short, medium and long term. In this context, integrated thinking is central, because it allows understanding the real scope of IR, which goes above and beyond reporting and can affect, among others, companies' strategy, organizational structure, and stakeholder management.

\section{CURRENT AND FUTURE RESEARCH ON IR}

Since 2013, when the IR Framework was first published, many researchers from several fields have investigated IR, its main features and the consequences for the companies implementing it (for a review, see de Villiers, Hsiao, \& Maroun, 2017; Dumay, Bernardi, Guthrie, \& Demartini, 2016; Mervelskemper \& Streit, 2017). This literature can be split into studies focused on IR from the perspective of the external users (among others, Bernardi \& Stark, 2018; Lai, Melloni, \& Stacchezzini, 2016; Serafeim, 2015; Zhou, Simnett, \& Green, 2017), from the perspective of the internal users, and from a management accounting and decision-making perspective (among others, Guthrie, Ricceri, Dumay, \& Nielsen, 2017; Mio, Fasan, \& Pauluzzo, 2016; Steyn, 2014; Stubbs \& Higgins, 2014). Interestingly, Barth, Cahan, Chen and Venter (2017) merge the two perspectives. They show that IR increases firm value and propose (and find empirical evidence on) two channels: better decision-making (real effect - internal) and improvement in the information environment (capital market effect - external).

Studies on the capital market channel (see Abhayawansa, Elijido-Ten, \& Dumay, 2018; Bernardi \& Stark, 2018; Flores et al., 2019; Zhou et al., 2017) have focused on financial analysts and have generally relied on voluntary disclosure (Beyer, Cohen, Lys, \& Walther, 2010) and information processing theory (Dhaliwal, Radhakrishnan, Tsang, \& Yang, 2012). Empirical results suggest that IR does improve corporate disclosure, thus increasing the ability of analysts to make better forecasts. Future research may study whether the increased ability of analysts is due to more information (thus leveraging on IR content elements) or to information being presented more effectively (thus leveraging on IR guiding principles).

Another interesting issue still underinvestigated is the role of IR assurance. NFI are often perceived by investors as being less reliable than financial information. Can assurance fill this gap in investors' confidence? Reimsbach, Hahn and Gürtürk (2017), for instance, find that assurance does play a central role for investors, but more studies are needed on this research question. In particular, researchers may tackle the issue of the assurance on forward-looking information, as pointed out below. Moreover, they may draw the attention on the expectation gap related to the scope of assurance, an extremely important element in this context, to the point that the assurance effectiveness should be evaluated in terms of the reduction in such expectation gap.

According to Perego, Kennedy and Whiteman (2016), much of the embryonic IR-related research has yet to explore how internal performance measurement and reporting systems have been impacted by the adoption of IR. This gap needs to be covered, because, according to the authors, experts have called for further applied research analyzing diffusion mechanisms across and within firms that are working on how to implement IR internally.

Some of the studies focusing on the internal implementation of IR ( Lodhia, 2015; Mio et al., 2016; Steyn, 2014; Stubbs \& Higgins, 2014, among others) generally explore the transition to integrated reporting, the drivers of change in the management control system, 
the changes in corporate processes and structures after the adoption of IR. De Villiers et al. (2017) develop a new conceptual model that can be used as a framework for understanding the various influences of IR and as a way of identifying new, interesting and underexplored research questions.

This second stream of research, generally based on qualitative methods, stems from integrating thinking, which makes the IR framework a powerful instrument to induce organization change that goes beyond the reporting and that potentially involves all functions of the company. With the recent EU Directive on NFI, the role of the board of directors is much more central, because of the higher degree of responsibility and judgement that it requires. Thus, further research on the interplay between corporate governance and IR is needed, especially when IR becomes mandatory.

Other research questions that deserve an analysis are related to target setting. If long-term performance is driven by NFI and by intangible assets, then managers should be held accountable for their performance in those areas and should be remunerated accordingly. Did the adoption of IR actually shape companies' MBO? Connected with this issue, there is the long-term orientation of adopting companies. Pushing managers to take decisions that allow companies to generate value in the long term is one of the main aims of IR. Also, by relying on the literature on the real effects of accounting, researchers may investigate whether companies implementing the IR framework (both reporting and integrated thinking) put more emphasis on long-term performance.

On the one hand, targets reflect an internal dimension of analysis. On the other hand, externalities refer to impact on stakeholders. Merging these two dimensions (internal and external) may be challenging. One of the tools that may be used to this purpose is to measure the impact of corporate operations towards other stakeholders. These impact indicators allow both internally communicating targets and measuring externalities. Academic literature can contribute to this field by proposing best practices and by studying the effects of impact indicators on both internal decision-making and on external stakeholders.

Forward-looking information are central in IR, as one of its most innovative features is the orientation to the future. If this kind of information is extremely relevant to investors, at the same time, it may damage the corporation because competitors may have access to proprietary information. How do companies react to this possible shortcoming? Do they omit any forward-looking information because of confidentiality issues? What is the process through which they decide which information to exclude? Who is in charge of this activity?

Finally, exploring the role of benchmarking is required. Nonfinancial, forward-looking indicators may lack relevance because investors do not have enough information to benchmark these indicators against other companies. It would be probably important for them to have a benchmark at the sector. Therefore, further research is needed not only on the quality and reliability of such disclosure but also on the way in which they are benchmarked against competitors.

There is an urgent need of "relevant" investigations in this field, which is able to impact on the quality of the companies and on the competitive arena and to improve business. The tracks summarized above represent a (little) contribution and guidance.

\section{REFERENCES}

Abhayawansa, S., Elijido-Ten, E., \& Dumay, J. (2018). A practice theoretical analysis of the irrelevance of integrated reporting to mainstream sell-side analysts. Accounting \& Finance, 59(3), 1615-1647. Retrieved from https://doi.org/10.1111/acfi.12367

Barth, M. E., Cahan, S. F., Chen, L., \& Venter, E. R. (2017). The economic consequences associated with integrated report quality: capital market and real effects. Accounting, Organizations and Society, 62, 43-64.

Bernardi, C., \& Stark, A. W. (2018). Environmental, social and governance disclosure, integrated reporting, and the accuracy of analyst forecasts. The British Accounting Review, 50(1), 1631. Retrieved from https://doi.org/10.1016/j.bar.2016.10.001

Besharov, M., \& Smith, W. K. (2014). Multiple institutional logics in organizations: explaining their varied nature and implications. Academy of Management Review, 39(3), 364-381.
Beyer, A., Cohen, D. A., Lys, T. Z., \& Walther, B. R. (2010). The financial reporting environment: review of the recent literature. Journal of Accounting and Economics, 50(2-3), 296-343. Retrieved from https://doi.org/10.1016/j.jacceco.2010.10.003

Daub, C. (2007). Assessing the quality of sustainability reporting: an alternative methodological approach. Journal of Cleaner Production, 15(1), 75-85.

De Villiers, C., Hsiao, P.-C. K., \& Maroun, W. (2017). Developing a conceptual model of influences around integrated reporting, new insights and directions for future research. Meditari Accountancy Research, 25(4), 450-460. Retrieved from https://doi.org/10.1108/MEDAR-07-2017-0183

Dhaliwal, D. S., Radhakrishnan, S., Tsang, A., \& Yang, Y. G. (2012). Nonfinancial disclosure and analyst forecast accuracy: international evidence on corporate social responsibility 
disclosure. The Accounting Review, 87(3), 723-759. Retrieved from https://doi.org/10.2308/accr-10218

Dumay, J., Bernardi, C., Guthrie, J., \& Demartini, P. (2016). Integrated reporting: a structured literature review. Accounting Forum, 40(3), 166-185. Retrieved from https://doi. org/10.1016/j.accfor.2016.06.001

Dunn, M. B., \& Jones, C. (2010). Institutional logics and institutional pluralism: the contestation of care and science logics in medical education, 1967-2005. Administrative Science Quarterly, 55(1), 114-149.

Guthrie, J., Ricceri, F., Dumay, J., \& Nielsen, C. (2017). The Routledge companion to intellectual capital. London: Routledge.

Flores, E., Fasan, M., Mendes-da-Silva, W., Oliveira Sampaio, J. (2019). Integrated reporting and capital markets in an international setting: The role of financial analysts. Business Strategy and the Environment, 28(7), 1465-1480. https://doi. org/10.1002/bse.2378

International Integrated Reporting Council. (2013). The International $<I R>$ Framework. Retrieved from https:// integratedreporting.org/wp-content/uploads/2013/12/13-1208-THE-INTERNATIONAL-IR-FRAMEWORK-2-1.pdf

Lai, A., Melloni, G., \& Stacchezzini, R. (2016). Corporate sustainable development: is 'integrated reporting' a legitimation strategy? Business Strategy and the Environment, 25(3), 165177. Retrieved from https://doi.org/10.1002/bse.1863

Lee, K., \& Yeo, G. H. (2016). The association between integrated reporting and firm valuation. Review of Quantitative Finance and Accounting, 47(4), 1221-1250. Retrieved from https://doi. org/10.1007/s11156-015-0536-y

Lodhia, S. (2015). Exploring the transition to integrated reporting through a practice lens: an Australian customer owned bank perspective. Journal of Business Ethics, 129(3), 585-598.
Mervelskemper, L., \& Streit, D. (2017). Enhancing market valuation of ESG performance: is integrated reporting keeping its promise? Business Strategy and the Environment, 26(4), 536-549. Retrieved from https://doi.org/10.1002/ bse. 1935

Mio, C., Fasan, M., \& Pauluzzo, R. (2016). Internal application of IR principles: generali's internal integrated reporting. Journal of Cleaner Production, 139, 204-218. Retrieved from https://doi.org/10.1016/j.jclepro.2016.07.149

Perego, P., Kennedy, S., \& Whiteman, G. (2016). A lot of icing but little cake? Taking integrated reporting forward. Journal of Cleaner Production, 136, 53-64. Retrieved from http://doi. org/10.1016/j.jclepro.2016.01.106

Reimsbach, D., Hahn, R., \& Gürtürk, A. (2017). Integrated reporting and assurance of sustainability information: an experimental study on professional investors' information processing. European Accounting Review, 27(3), 559-581.

Serafeim, G. (2015). Integrated reporting and investor clientele. Journal of Applied Corporate Finance, 27(2), 34-51. Retrieved from https://doi.org/10.1111/jacf.12116

Steyn, M. (2014). Organisational benefits and implementation challenges of mandatory integrated reporting: Perspectives of senior executives at South African listed companies. Sustainability Accounting, Management and Policy Journal, 5(4), 476-503. Retrieved from https://doi.org/10.1108/ SAMPJ-11-2013-0052

Stubbs, W., \& Higgins, C. (2014). Integrated reporting and internal mechanisms of change. Accounting, Auditing \& Accountability Journal, 27(7), 1068-1089. Retrieved from https://doi.org/10.1108/AAAJ-03-2013-1279

Zhou, S., Simnett, R., \& Green, W. (2017). Does integrated reporting matter to the capital market? Abacus, 53(1), 94-132. Retrieved from https://doi:10.1111/abac.12104 